\title{
The Burden of Neonatal Mortality in Urban Slums of Bangladesh: Evidence from Bangladesh Urban Health Survey 2013 Data
}

\author{
Ummay Nayeema Islam and Tasmiah Sad Sutopa* \\ Department of Statistics, University of Dhaka, Dhaka-1000, Bangladesh
}

(Received: 5 July 2020; Accepted: 24 February 2021)

\begin{abstract}
Children in slums are in a vulnerable situation because of their low living standard and poor access to healthcare services. It is melancholic that newborns are the worst victims of this devastating condition. This paper aims at finding out the potential determinants of neonatal death in urban slums using Bangladesh Urban Health Survey 2013 data. For the purpose of analyses, bivariate analysis has been conducted using chi-square test and multiple logistic regression model is used to assess the adjusted effects of potential determinants of neonatal mortality in slum area. Results indicate that type of birth, mother's education, working status, NGO membership, migration status, pregnancy complication and water source played significant role in occurring neonatal death in slum areas. In order to reduce neonatal mortality in slums, migrant mothers should get the highest priority; awareness building programs should be held frequently in slums regarding maternal health and health care practices for the pregnant mothers as well as their newborn babies.
\end{abstract}

Keywords: Neonatal death, Urban slum, Logistic regression

\section{Introduction}

It is observed in recent years that Bangladesh has been experiencing a rapid but unplanned urbanization. It is projected that by 2050 the urban population will encompass more than half of Bangladesh's total population'. Slum settlements have been rising as a consequence of this trend with a recent census counting approximately 14000 slum settlements across the country ${ }^{2}$. This growing urban poor population in this country is an increasing challenge for local health authorities. Consequently, the adverse effect of urbanization is making an expression on child death in slum areas, especially, on neonatal death.

Neonatal period (the first 28 days of life) is the most crucial period in a child's life because this period carries the highest risk of death than any other period during the childhood. In 2018 an estimated 5.3 million death occurred in the first five years with almost half of these in the first four weeks of life $^{3}$. Whereas high income countries maintain a neonatal mortality rate (NMR) of 2-3 per 1000 live births, Bangladesh as one of the most successful achievers of MDG of Asia, is still struggling to control neonatal mortality with a high NMR of 28 per 1000 live births ${ }^{4}$.

Although infant and child mortality is less pronounced in urban areas than rural areas, it is significantly higher among urban poor, especially, among the slum population ${ }^{5-7}$. The situation is getting worse in the country's urban slums with a neonatal mortality rate of 31.0 per 1000 live births ${ }^{8}$. It is high time we gave our attention to these people and work intensely on reducing child mortality in these areas.

Despite many researches have been conducted on neonatal mortality, very few have focused on urban slums. By using verbal autopsy questionnaire, Khatun et al. examined causes of neonatal and maternal death in slums in three areas of Dhaka city'. Awasthi and Pande revealed specific causes of under-five mortality in urban slums of Lucknow,
North India ${ }^{\mathbf{1 0}}$. Keraka and Wamicha attempted to examine the impact of slum environments on child mortality and morbidity in slums along Nirobi river ${ }^{11}$. A retrospective study was conducted by Vaid et al. and analyzed data on infant mortality in urban slum area in Vellore ${ }^{12}$. In the light of above, this paper has strived to investigate the potential risk factors of neonatal mortality in urban slums by using Bangladesh Urban Health Survey (BUHS) 2013 data as well as policy recommendations have been given so that neonatal mortality can be reduced.

\section{Data and Variables}

This paper assessed neonatal mortality in City Corporation slum areas where BUHS 2013 data was used to meet the purpose. BUHS 2013 performed three stage stratified sampling procedure where random selection of 450 and 184 Mohollas from City Corporations and other urban areas was conducted at the first stage. By performing a mapping activity only in City Corporation strata, two slums and one non-slum clusters were chosen from each selected Mohalla. Whereas, in other urban areas two clusters were randomly selected. Finally, third stage comprised of a random selection of households from each cluster which resulted in 53,790 households. Of the households, BUHS interviewed 15-49 ever married women and gathered information on individual household characteristics, birth history, migration status, family planning, child health and nutrition and maternal health care practices ${ }^{8}$.

Neonatal death status was considered as response variable to find the key determinants of neonatal mortality among children in slums which is a binary variable taking value 1 if the child died within 28 days and 0 otherwise.

Based on extensive exploration of previous literature ${ }^{13-16}$, explanatory variables considered in this study were: first birth (yes, no), gender of child (girl, boy), type of birth (single, multiple),mother's age at $\operatorname{birth}(<20$ years, 20-30 years, >30 years), attended school/madrasa (yes, no), 
working status (working, not working), media exposure (exposed, unexposed), NGO membership (member, nonmember), migration status (migrant, non-migrant), pregnancy complications (yes, no), place of delivery (home based, hospital based) and water source (improved, unimproved). Moreover, some variables were constructed from available information of the survey. In this study, only the recent migrants, i.e., who were residing in the current city for not more than two years, were considered as migrants. Women pertaining to any of the following organization: Grameen Bank, BRAC, BRDB, ASHA and PROSHIKA were treated as NGO members. Mothers who experienced complications (convulsion/fits, heavy bleeding, prolonged labor, high fever, oedema) during last pregnancy were codified as having complication. Piped, tube well water, protected well/ spring, rain water and bottled water were categorized as improved source of drinking water and unimproved source included unprotected well/ spring, surface water and others.

The 2013 BUHS consisted of a total of 4066 slum dwellers over the three years preceding the survey. Among them 59 lost their lives before completing 1 month. Thus, the approximate result of neonatal mortality rate (NMR) in City Corporation slum areas was 15 per 1000 live births.

This paper examined both unadjusted and adjusted effects of selected explanatory variables where unadjusted effects were measured by bivariate analysis. Multiple logistic regression model (MLRM) is applied to dataset using the software SPSS (Statistical Package for Social Sciences) version 20 for adjusting the unadjusted effects of the variables.

\section{Results}

Table 1 displayed information of descriptive statistics on selected covariates. It was noticed that among the slum children, proportion of girls (48.6\%) and boys (51.4\%) was almost same. Of them $39.6 \%$ were the first birth of their parents and most of the delivery resulted in singleton babies (99.3\%). The result evolved that the highest birth occurred at age group 20-30 and the least birth occurred above 30 years of age. Among the slum mothers, a significant percentage $(76.1 \%)$ had attended school/madrasa and only $23.9 \%$ involved in working activities.

Again, Table 1 revealed that in slum areas, access to media percentage (85\%) was high. A large number of respondents $(84.1 \%)$ were engaged with NGO. $90.7 \%$ of slum dwellers were non-migrants or long-term migrants whereas only 9.3\% were recent migrants. At the time of last pregnancy, $79.8 \%$ mothers wanted to be conceived and $71.9 \%$ took antenatal care services during pregnancy period. Moreover, $32.2 \%$ suffered from various complications during their last pregnancy. Apart from that more than half of the deliveries took placed at home $(60.3 \%)$. The result provided the findings that most of the households collected water from improved sources for drinking or other household activities where $0.3 \%$ used unimproved sources of water.
Bivariate analysis comprised of forming contingency tables along with row percentages to determine the distribution of neonatal death for each category of predictor variables. Further association between neonatal death and included covariates has been measured through Chi-square test.

Table 1. Descriptive Statistics of Selected Covariates with Percentages of Neonatal Mortality along with p-values obtained from Chi-square test

\begin{tabular}{|c|c|c|c|c|}
\hline \multirow[b]{2}{*}{ Covariates } & \multirow[b]{2}{*}{ Percentage } & \multicolumn{2}{|c|}{ Neonatal Death Status } & \multirow[b]{2}{*}{$\begin{array}{l}\text { p- } \\
\text { value }\end{array}$} \\
\hline & & $\begin{array}{l}\text { Death } \\
(\%)\end{array}$ & Alive (\%) & \\
\hline \multicolumn{5}{|l|}{ First Birth } \\
\hline Yes & 39.6 & $23(1.4)$ & 1587(98.6) & \multirow{2}{*}{0.903} \\
\hline No & 60.4 & $36(1.5)$ & $2420(98.5)$ & \\
\hline \multicolumn{5}{|c|}{ Gender of Child } \\
\hline Girl & 48.6 & $27(1.4)$ & 1948(98.6) & \multirow{2}{*}{0.663} \\
\hline Boy & 51.4 & $32(1.5)$ & $2059(98.5)$ & \\
\hline \multicolumn{5}{|l|}{ Type of Birth } \\
\hline Single & 99.3 & $55(1.4)$ & 3981(98.6) & \multirow{2}{*}{$<0.001$} \\
\hline Multiple & 0.7 & $4(13.3)$ & $26(86.7)$ & \\
\hline \multicolumn{5}{|c|}{ Mother's Age at Birth } \\
\hline$<20$ years & 28.9 & $11(0.93)$ & 1163(99.1) & \multirow{3}{*}{0.079} \\
\hline 20-30 years & 57.2 & $35(1.5)$ & 2292(98.5) & \\
\hline$>30$ years & 13.9 & $13(2.3)$ & $552(97.7)$ & \\
\hline \multicolumn{5}{|c|}{ Attended School/Madrasa } \\
\hline Yes & 76.1 & $38(1.2)$ & $3055(98.8)$ & \multirow{2}{*}{0.034} \\
\hline No & 23.9 & $21(2.2)$ & $952(97.8)$ & \\
\hline \multicolumn{5}{|c|}{ Working Status } \\
\hline Working & 24.9 & $23(2.3)$ & 991(97.7) & \multirow{2}{*}{0.012} \\
\hline Not working & 75.1 & $36(1.2)$ & $3016(98.8)$ & \\
\hline \multicolumn{5}{|c|}{ Media Exposure } \\
\hline Exposed & 85 & $50(1.4)$ & $3406(98.6)$ & \multirow{2}{*}{0.956} \\
\hline Unexposed & 15 & $9(1.5)$ & $601(98.5)$ & \\
\hline \multicolumn{5}{|c|}{ NGO Membership } \\
\hline Member & 15.9 & $15(2.3)$ & $630(97.7)$ & \multirow{2}{*}{0.043} \\
\hline Non-member & 84.1 & $44(1.3)$ & 3377(98.7) & \\
\hline \multicolumn{5}{|c|}{ Migration Status } \\
\hline Migrant & 9.3 & $12(3.2)$ & $367(96.8)$ & \multirow{2}{*}{0.003} \\
\hline Non-migrant & 90.7 & $47(1.3)$ & 3640(98.7) & \\
\hline \multicolumn{5}{|c|}{ Wanted Pregnancy } \\
\hline Yes & 79.8 & $46(1.4)$ & 3199(98.6) & \multirow{2}{*}{0.723} \\
\hline No & 20.2 & $13(1.6)$ & $808(98.4)$ & \\
\hline Received AN & & & & \\
\hline Yes & 71.9 & $42(1.4)$ & 2882(98.6) & 0000 \\
\hline No & 28.1 & $17(1.5)$ & $1125(98.5)$ & 0.900 \\
\hline Pregnancy $\mathrm{C}$ & mplication & & & \\
\hline Yes & 32.2 & $31(2.4)$ & $1280(97.6)$ & \\
\hline No & 67.8 & $28(1.0)$ & 2727(99) & 0.001 \\
\hline Place of Deliv & & & & \\
\hline Home-based & 60.3 & $34(1.4)$ & 2418(98.6) & \\
\hline $\begin{array}{l}\text { Hospital- } \\
\text { based }\end{array}$ & 39.7 & $25(1.5)$ & 1589(98.5) & 0.672 \\
\hline Water Sourc & & & & \\
\hline Improved & 99.7 & $58(1.4)$ & 3996(98.6) & \\
\hline Unimproved & 0.3 & $1(8.3)$ & $11(91.7)$ & 0.046 \\
\hline
\end{tabular}

Table 1 presented these percentage distributions and the pvalues obtained from Chi-square test. It was observed that the covariates type of birth, mother's age at birth, attended school, working status, NGO membership, migration status, having complications and water source were significantly associated with exposed variable as the p-values were too 
small. Moreover, Chi-square test gives message only the association between dependent variable (categorical) and independent variables (categorical) but doesn't expose the casual relation between them. The variables found to have significant association in bivariate section were further incorporated in regression analysis for estimating the adjusted effects of these variables. After applying MLRM, the fixed effects were presented in Table 2 including estimates, standard errors, odds ratios and the corresponding $\mathrm{p}$-values where null hypothesis refers to the no impact of specified covariate on neonatal death status.

Table 2. Estimates of regression coefficients, standard errors (SE), odds ratios (OR) of neonatal death along with p-values obtained from multiple logistic regression model

\begin{tabular}{|c|c|c|c|c|}
\hline Covariates & Estimates & SE & OR & p-value \\
\hline \multicolumn{5}{|l|}{ Type of Birth } \\
\hline Single & -2.228 & 0.579 & 0.108 & $<0.001$ \\
\hline Multiple (RC) & - & - & - & 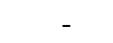 \\
\hline \multicolumn{5}{|c|}{ Mother's Age at Birth } \\
\hline$<20$ years & -0.385 & 0.356 & 0.680 & 0.280 \\
\hline $20-30$ years $(\mathrm{RC})$ & & - & - & \\
\hline$>30$ years & 0.299 & 0.339 & 1.348 & 0.378 \\
\hline \multicolumn{5}{|c|}{ Attended School/ Madrasa } \\
\hline Yes & -0.508 & 0.286 & 0.601 & 0.076 \\
\hline No $(\mathrm{RC})$ & - & - & . & \\
\hline \multicolumn{5}{|l|}{ Working Status } \\
\hline Working & 0.591 & 0.276 & 1.805 & 0.032 \\
\hline $\begin{array}{l}\text { Not working } \\
(\mathrm{RC})\end{array}$ & - & - & - & \\
\hline \multicolumn{5}{|l|}{ NGO Membership } \\
\hline Member & 0.591 & 0.310 & 1.805 & 0.057 \\
\hline $\begin{array}{l}\text { Non-member } \\
\text { (RC) }\end{array}$ & - & - & - & - \\
\hline \multicolumn{5}{|l|}{ Migration Status } \\
\hline Migrant & 1.043 & 0.337 & 2.839 & 0.002 \\
\hline $\begin{array}{l}\text { Non-migrant } \\
\text { (RC) }\end{array}$ & - & - & - & - \\
\hline \multicolumn{5}{|c|}{ Pregnancy Complication } \\
\hline Yes & 0.868 & 0.267 & 2.381 & 0.001 \\
\hline No (RC) & - & - & - & \\
\hline \multicolumn{5}{|l|}{ Water Source } \\
\hline Improved & -2.114 & 1.086 & 0.121 & 0.052 \\
\hline $\begin{array}{l}\text { Unimproved } \\
\text { (RC) }\end{array}$ & - & - & - & - \\
\hline
\end{tabular}

It was resulted in Table 2 that singleton babies had experienced $89.2 \%$ lower odds of death within 28 days of their lives than multiple births (twin, triplets etc.) and the result was highly significant at $1 \%$ level of significance (pvalue $<0.001)$. The regression model depicted that risk of neonatal death was significantly lower $(\mathrm{OR}=0.601$, pvalue $=0.076$ ) whose mothers attended at any educational institution (school/madrasa) than the illiterate mothers. Again, noticeable result had been found for the working mothers $(p$-value $=0.032)$. The children of working mothers had $80.5 \%$ higher odds of occurring death than the children of unemployed mothers. Again, odds of occurring event of interest was $80.5 \%$ higher among the children whose mothers had NGO membership and this finding was significant at $10 \%$ level of significance ( $\mathrm{p}$-value $=0.057$ ). Neonatal death was greater $(\mathrm{OR}=2.839)$ in slum among the migrant mothers than the non-migrant mothers along with p-value of 0.002 . Having complication had a great impact on the survival of young children with the p-value (0.001) at $1 \%$ level of significance. The mothers having complications during last pregnancy had $138.1 \%$ higher odds of neonatal death than the mothers who experienced no complication. The household which collected water from improved sources had $87.9 \%$ lower odds of occurring neonatal death than those of unimproved sources of water.

\section{Discussion}

Bangladesh is going through urbanization with an annual rate of 3.17 percent where 36.6 percent of the country's total population is now living in urban areas ${ }^{17}$. Slums have grown at a disproportionate rate ${ }^{18}$ and they struggle with poor housing, water and sanitation system ${ }^{19}$. Although Bangladesh has made remarkable progress in the provision of health care with neonatal mortality rates cut by more than half between 1990 and 2010 at the national level ${ }^{20}$, significant challenges still persist. It is a grim irony that the poverty-stricken people in slums cannot access to proper health care services. Thus, health outcomes are historically worse in slums where neonatal death occurs at a significant rate.

In this paper the factors associated with neonatal death among slum dwellers are examined through statistical analysis. This study showed a reduced risk of neonatal mortality for singletons compared to twins or multiples. Twins and triplets carry a greater risk of being born with less maturity and less birth weight ${ }^{21}$. Moreover, the slum mothers are not privileged with modern curative services when their twins are at critical situations, which made these innocent children susceptible to death. Slum-mothers association with NGO resulted in an adverse effect on neonatal survival. The poverty-stricken women who take micro-credits from NGOs can hardly manage proper newborn care which led the babies to unlucky early death. Mother's education is inextricably related with their children's survival. Consistent with earlier studies ${ }^{22-24}$, this study findings revealed that the mothers who attended educational institutions, experienced lower risk of neonatal mortality than the mothers who were ignorant. Mother's education reflects her skills and choices in child's heath care practices. Educated mothers can take immediate steps regarding their child health if they notice something abnormal symptoms. Hence, mothers in slums who have at least primary educational background can protect their newborns from neonatal death. The result disclosed a negative consequence of working status of mother on their newborn kids which supported the previous literature ${ }^{25}$. Children of working mothers experienced a greater risk of mortality within 1-28 days than children of mothers who did not work outside the home to earn cash. The fact is that these working mothers in slum areas are extremely poor and generally come from a lower socio-economic status and 
work mainly in non-formal sectors including domestic helpers of other people's houses. They need to put a lot of physical effort as well as time in workplaces resulting in irregular breast feeding/ bathing and other newborn cares. Moreover, unavailability of maternity leaves along with huge workloads act as impediments for the mothers taking proper care of herself during pregnancy as well as her newly born children. It was ascertained that being born to a mother who had complications during pregnancy was associated with an increased risk of neonatal death. Numerous life-threatening pregnancy complications like vaginal bleeding, convulsion or prolonged labor are liable to ruin the immense joy of motherhood resulting in unfavorable outcomes such as maternal death, newborn death or birth with physical disabilities. Levels of neonatal mortality also vary considerably because of using categories of water sources. It was noticeable that using unimproved source of water for drinking or other household activities brought out life threatening diseases like diarrhea, cholera and typhoid to the newborn babies. Children are more vulnerable to health hazards associated with unimproved water supply and it is evident from past studies ${ }^{\mathbf{2 6}, 27}$ that access to improved water sources lessens the threat of diseases like diarrhea which reduces the child mortality. The study claimed that slum migrants appeared to be greatly disadvantaged in terms of neonatal survival. Child survival was lower among migrant mothers than those of non-migrants ${ }^{28}$. The migrant mothers rushing to town with the hope of better lifestyle have to struggle for meeting daily needs which cost them being inaccessible to health care services for neonates. It may lead to vulnerable neonatal death among slum dwellers who are migrant.

\section{Conclusion}

This study emphasizes on determining the factors which are highly responsible for occurring child death during its first four weeks of life in urban slums. Some effective measures can be implemented to mitigate the issues responsible for child mortality. In any strategy to reduce neonatal death, focus should be given to the migrant slum mothers so that they can get enough access to the health care services because during pregnancy early and frequent antenatal care can help identify high risk pregnancies that require multiple interventions for maternal and newborn health. Additionally, education should be made compulsory to the slum mothers. Since most of these mothers are engaged in various wage-earning activities, awareness building programs should be held on feeding practices or other newborn health care practices for the working mothers. Mothers who are connected to NGOs should be taken care of so that they have proper knowledge on newborn care. Moreover, covering up all the unprotected sources of water and possibly installing hand pumps or mechanical pumps at the wells could improve the situation. This study does not consider any cluster effect and it ignores the confounding effects of related variables.

\section{Acknowledgement}

The authors are thankful to National Institute of Population Research and Training (NIPORT), Bangladesh for providing Bangladesh Urban Health Survey 2013 data. The authors are also grateful to Professor Dr. Wasimul Bari, Department of Statistics, University of Dhaka, for his valuable suggestions in various stages of this study.

\section{References}

1. United Nations Department of Economic and Social Affairs (UN DESA). World Urbanization Prospects: The 2014 Revision. United Nations, New York: UN DESA, 2015.

2. Bangladesh Bureau of Statistics. Preliminary Report on the Census of Slum Areas and Floating Population 2014. Dhaka, Bangladesh: Bureau of Statistics, 2015.

3. World Health Organization (WHO). More Women and Children Survive Today than Ever Before-UN Report. Geneva, New York: WHO, 2019.

4. National Institute of Population Research and Training (NIPORT), Mitra and Associates,andICF International. Bangladesh Demographic and Health Survey 2014. Dhaka, Bangladesh and Calverton, Maryland, USA: Mitra and Associates, and ICF International, 2016.

5. Ravallion, M., 2002. On the Urbanization of Poverty. Journal of Development Economics, 68, 435-442.

6. National Institute of Population Research and Training (NIPORT), Mitra and Associates, and ORC Macro. Bangladesh Demographic and Health Survey 2004. Dhaka, Bangladesh and Calverton, Maryland, USA: Mitra and Associates, and ORC Macro, 2005.

7. National Institute of Population Research and Training (NIPORT), Mitra and Associates,and Macro International. Bangladesh Demographic and Health Survey 2007. Dhaka, Bangladesh and Calverton, Maryland, USA: Mitra and Associates, and Macro International, 2009.

8. National Institute of Population Research and Training (NIPORT), MEASURE Evaluation, International Centre for Diarrhoeal Disease Research, Bangladesh (ICDDR,B), and Associates for Community and Population Research (ACPR). Bangladesh Urban Health Survey 2013. Dhaka, Bangladesh and Chapel Hill, NC, USA: NIPORT, MEASURE Evaluation, ICDDR,B, and ACPR, 2008.

9. Khatun, F., S. Rasheed, A.C. Moran, A.M. Alam, M.S. Shomik, M. Sultana, N. Chowdhury, M. Iqbal and A. Bhuiya, 2012. Causes of Neonatal and Maternal Deaths in Dhaka slums: Implications for Service Delivery. BMC Public Health, 12(1), 84.

10. Awasthi, S. and V.K. Pande, 1998. Cause-specific Mortality in Under Fives in the Urban Slums of Lucknow, North India. Journal of Tropical Pediatrics, 44(6), 358-361.

11. Keraka, M.N. and W.N. Wamicha, 2003. Child Mortality and Morbidity in Slum Environments along Nairobi River. Eastern Africa Social Science Research Review, 19(1), 4157.

12. Vaid, A., A. Mammen, B. Primrose and G. Kang, 2007. Infant Mortality in an Urban Slum. The Indian Journal of Pediatrics, 74(5), 449-453. 
13. Titaley, C.R., M.J. Dibley, K. Agho, C.L. Roberts and J. Hall, 2008. Determinants of Neonatal Mortality in Indonesia. BMC Public Health, 8(1), 232.

14. Maniruzzaman, M., H.S. Suri, N. Kumar, M.M. Abedin, M.J. Rahman, A. El-Baz, M. Bhoot, J.S. Teji and J.S. Suri,2018. Risk Factors of Neonatal Mortality and Child Mortality in Bangladesh. Journal of Global Health, 8(1).

15. Kamal, S.M., M. Asrafuzzaman and S.A. Nasreen,2012. Risk Factors of Neonatal Mortality in Bangladesh. Journal of Nepal Paediatric Society, 32(1), 37-46.

16. Al Kibria, G.M., R. Khanam, D.K. Mitra, A. Mahmud, N. Begum, S.M.I. Moin, S.K. Saha, A. Baqui and P.S.G. in Bangladesh, 2018. Rates and Determinants of Neonatal Mortality in Two Rural Sub-districts of Sylhet, Bangladesh. Plos One, 13(11).

17. Central Intelligence agency. n.d. "The World Facebook: Bangladesh".

18. Adams, A.M., H.Y. Nababan and S.M.A. Hanifi, 2015. Building Social Networks for Maternal and Newborn Health in Poor Urban Settlements: A Cross-sectional study in Bangladesh. Plos One, 10(4).

19. Uddin, N.,2018. Assessing Urban Sustantiability of Slum Settlements in Bangladesh: Evidence from Chittagong City. Journal of Urban management, 7(1), 32-42.

20. Bender, H., T. Peter, K. Annie, C. Jacquelyn and L. Ana, 2014. The Manoshi Project: Bringing Quality Maternal Care to Poor Women in Urban Bangladesh. Harvard School of Public Health and Maternal Health Task Force.

21. Ruk, R.J., C.E. Brown, M.T. Peters and A.B. Johnston, 2001. Specialized Care for TWIN gestation: Improving Newborn
Outcomes Reducing Costs. Journal of Obstetric, Gynecologic and Neonatal Nursing, 30(1), 52-60.

22. Abuqamar, M., D. Coomans and F. Louckx, 2011. The Impact of Parental Education on Infant Mortality in Gaza Strip, Palestine. Journal of Public Health and Epidemiology, 3(1),28-33.

23. Alam, N., J.K. Van Ginneken and A.M. Bosch, 2007. Infant Mortality among Twins and Triplets in Rural Bangladesh in 1975-2002. Tropical Medicine and International Health,12(12), 1506-1514.

24. Singh, G.K. and M.D. Kogan, 2007. Persistent Socioeconomic Disparities in Infant, Neonatal and Postneonatal Mortality Rates in the United States, 1969-2001. Pediatric, 119(4), 928939.

25. Basu, A.M. and K. Basu, 1991. Women's Economic Roles and Child Survival: The Case of India. Health Transition Review, 83-103.

26. Aiello, A.E, E.L. Larson and R. Sedlak, 2008. Hidden Heroes of the Health Revolution Sanitation and Personal Hygiene. American Journal of Infection Control, 36(10), S128-S151.

27. Fink, G., I. Gunther, and K. Hill, 2011. The Effect of Water and Sanitation on Child Health: Evidence from Demographic and Health Surveys 1986-2007. International Journal of Epidemiology, 40(5), 1196-1204.

28. Islam, M.M. and K.M.A.K. Azad, 2008. Rural-urban Migration and Child Survival in Urban Bangladesh: Are the Urban Migrants and Poor Disadvantaged? Journal of Biosocial Science, 40(1), 83-96. 
